\title{
Oxidation resistance improvement of Ti-50Al intermetallics by pre-oxidizing and subsequent polishing
}

\author{
Mu-Rong Yang, S.K. Wu* \\ Institute of Materials Science and Engineering, National Taiwan University, 106 Taipei, Taiwan, ROC
}

Received 17 August 1999; received in revised form 15 January 2000; accepted 18 January 2000

\begin{abstract}
The oxidation resistance of Ti-50Al intermetallics has been improved by pre-oxidizing at $800^{\circ} \mathrm{C} \times 48 \mathrm{~h}$ in air and subsequently polishing the outer $\mathrm{TiO}_{2}$ layer of the oxide scale. The cyclic oxidation resistance's at $800^{\circ} \mathrm{C}$ of the per-oxidized and polished specimens are substantially improved and the oxidation kinetics follow the parabolic rate law. This means that the outermost alumina-rich layer of the pre-oxidized and polished specimens is protective against oxidation at $800^{\circ} \mathrm{C}$ in air. This characteristic is attributed to the compressive stress relief associated with the removal of the outer $\mathrm{TiO}_{2}$ layer. The stress relief will alleviate cracking or rupture of the scales and simultaneously reduce the stress-assisted diffusion in the scale. At the same time, the catalytic effect of outer rutile titania may also play a detrimental role in the oxidation resistance of TiAl at high temperature. (C) 2000 Elsevier Science S.A. All rights reserved.
\end{abstract}

Keywords: Ti-50Al intermetallics; High-temperature oxidation resistance; Pre-oxidizing and polishing; Stress relief; Catalytic effect

\section{Introduction}

Titanium aluminides have been investigated for aerospace and industrial applications in intermediate temperatures $\left(600-850^{\circ} \mathrm{C}\right)$ due to their high specific mechanical properties and satisfactory creep resistance [1-2]. However, the room temperature brittleness and poor oxidation resistance at temperature above $700^{\circ} \mathrm{C}$ retard $\mathrm{TiAl}$ from practical applications. Some studies show that the room temperature ductility of TiAl intermetallics can be enhanced to a desired level of about 3-4\% tensile elongation by alloying design and/or microstructural control [3-5], but they do not generally form a long-lasting protective alumina scales in spite of their high aluminum content. The oxide layer of binary TiAl alloys oxidized in air especially at the temperature range $750-800^{\circ} \mathrm{C}$, consists of an outer $\mathrm{TiO}_{2}$ layer, an $\mathrm{Al}_{2} \mathrm{O}_{3}$-enriched layer, and an inner intermixed $\mathrm{Al}_{2} \mathrm{O}_{3} / \mathrm{TiO}_{2}$ layer [6-9]. A desired continuous $\mathrm{Al}_{2} \mathrm{O}_{3}$ scale does not form in air and this results in an inadequate oxidation resistance for titanium aluminides. Obviously, a continuous $\mathrm{Al}_{2} \mathrm{O}_{3}$ layer with an extremely slow and parabolic oxidation rate is the prerequisite for improving oxidation resistance of TiAl intermetallics at temperature above $700^{\circ} \mathrm{C}$ [10].

\footnotetext{
* Corresponding author. Tel.: +886-02-2363-7846; fax: +886-02-2363-4562.

E-mail address: skw@ccms.ntu.edu.tw (S.K. Wu)
}

Continuous $\mathrm{Al}_{2} \mathrm{O}_{3}$ film on TiAl intermetallics coated by chemical vapor deposition (CVD) can improve the isothermal oxidation resistance substantially, but this coating fails in cyclic oxidation performance [11]. A thin and condense $\mathrm{Al}_{2} \mathrm{O}_{3}$ surface layer can be formed by pre-oxidation of TiAl in a low partial pressure oxygen atmosphere [7] or pre-oxidation of TiAl packed with oxide powders, such as chromia [12], rutile [13] or silica [14] in inert atmosphere or in vacuum. In this study, a novel method is used to improve the oxidation resistance of Ti-50Al alloy which is obtained by the removal of the outer $\mathrm{TiO}_{2}$ layer on TiAl intermetallics pre-oxidized in air. The resistance to the subsequent cyclic oxidation of the specimens in air prepared by this method is also evaluated and discussed.

\section{Experimental procedures}

An ingot of Ti-50Al intermetallics was prepared by vacuum arc remelter, and then homogenized at $1050^{\circ} \mathrm{C}$ for $75 \mathrm{~h}$ in vacuum. Specimens in the form of coupons were cut from the ingot, polished to 600 grit paper, cleaned with acetone and ethanol, respectively, and finally rinsed with de-ionized water. Pre-oxidization was carried out in air at $800^{\circ} \mathrm{C}$ for 2 days (Fig. 1(a)) and then the outer white oxide scale was removed by polishing it on a cloth impregnated with $0.3 \mu \mathrm{m}$ alumina. The oxidation behaviors of the 

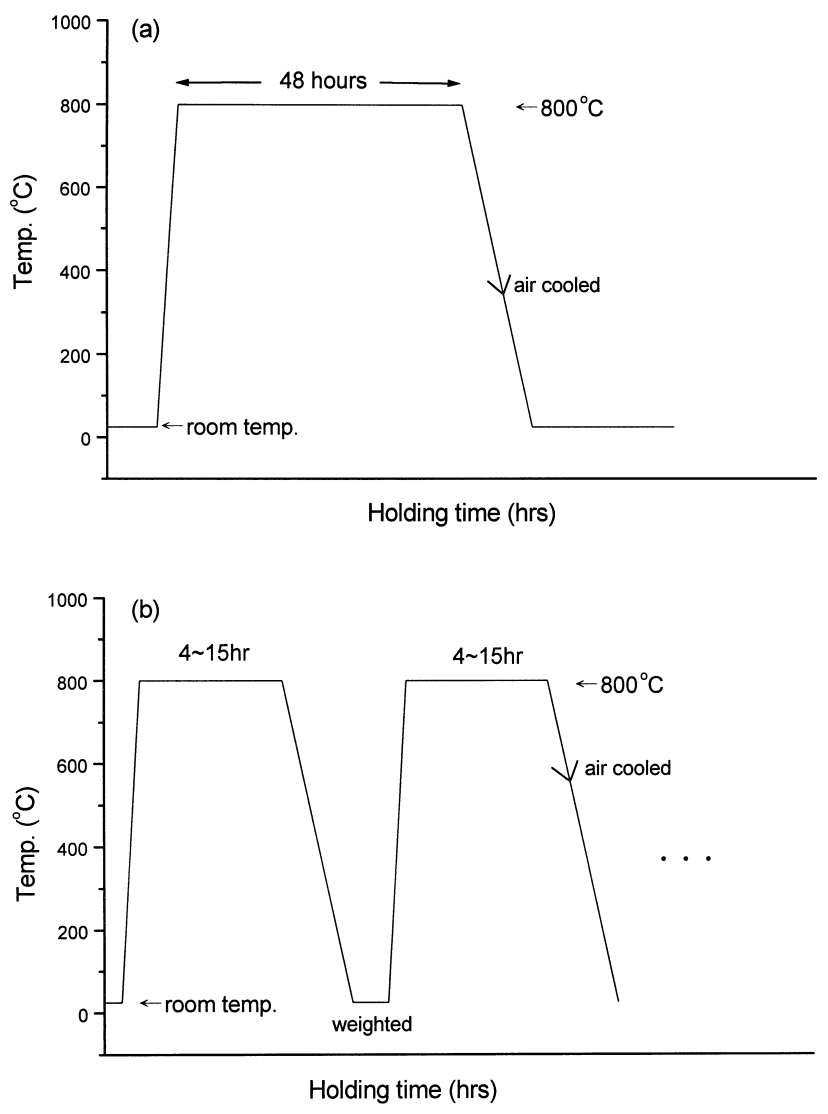

Fig. 1. The schematical diagram of oxidation procedures. (a) pre-oxidation; (b) cylic oxidation test.

pre-oxidized and subsequently polished specimens were characterized by exposing the specimen in $800^{\circ} \mathrm{C}$ static air and removing it regularly from the muffle furnace, air cooled, weighed and returned to the $800^{\circ} \mathrm{C}$ furnace again, as shown schematically in Fig. 1(b). The weight gains per exposed area $\left(\mathrm{mg} \mathrm{cm}^{-2}\right)$, weighed on an analytical balance to an accuracy of $\pm 10^{-3} \mathrm{mg}$, are calculated to evaluate the oxidation properties. Some pre-oxidized and polished specimens were deposited pure Ti film with $0.8 \mu \mathrm{m}$ thickness by $\mathrm{rf}$ magnetron sputtering.

The crystal structure of oxide scales was determined by X-ray diffraction (XRD) using Rigaku-IIB X-ray diffractometer with $\mathrm{Cu} \mathrm{K \alpha}$ radiation at $45 \mathrm{kV}, 30 \mathrm{~mA}$ and $0.03^{\circ}(2 \theta) \mathrm{s}^{-1}$ scanning rate at a grazing angle of $3^{\circ}$. To preserve the oxide scale during metallographic preparation, the electroless nickel was coated on the oxide scale [15]. The morphological observation was carried out by scanning electron microscopy (SEM) of Philips XL30, equipped with the energy dispersive spectrometry (EDS).

\section{Results and discussion}

After the continuous exposure in $800^{\circ} \mathrm{C}$ air for $48 \mathrm{~h}$, as indicated in Fig. 1(a), Ti-50Al forms a white and fragile ox- ide scale on the surface. Fig. 2 shows the SEM image and $\mathrm{O}$, Ti and $\mathrm{Al}$ mappings of specimen oxidized at $800^{\circ} \mathrm{C}$ for $48 \mathrm{~h}$. Very thick oxide scale $(\sim 5.5 \mu \mathrm{m})$ is formed with an outer titania layer (I), an alumina-rich layer (II) and an intermixed titania/alumina layer (III) beneath the oxide scale. At the interface of TiAl and oxide scale, an Al-depleted layer (IV) is found. The layer IV is presumably formed due to a net Al-consumption during the course of oxidation. The structural features of Fig. 2(a) are almost the same as those reported in the literature [6-9].

The polishing procedure can easily remove the top layer (layer I) of the oxide scale and leave the alumina-enriched layer (layer II) as the outermost one, as shown in Fig. 3. The opening between the oxide layer II and Ni coating results from the poor affinity of the electroless $\mathrm{Ni}$ plating to the alumina-enriched layer. The phases of oxide layers before and after the polishing procedure can be identified by the XRD patterns, as shown in Fig. 4. The removal of white oxide layer I by polishing can substantially reduce the intensity of rutile titania and slightly decrease the intensity of the $\alpha$-alumina. This indicates that the polishing procedure can remove the titania-abundant layer (layer I) of Fig. 2.

According to the procedure of Fig. 1(b), the cyclic oxidation curve performed at $800^{\circ} \mathrm{C}$ for the specimen of Fig. 3 is given in Fig. 5. That for the as-homogenized Ti-50Al specimen without pre-oxidation and polishing treatment, denoted as the as-homogenized Ti-50Al specimen, is also shown in Fig. 5. From Fig. 5, the as-homogenized Ti-50Al specimen has a much higher cyclic oxidation rate and its oxidation curve is so scattered due to the scale spallation. This means that the oxide scale on the as-homogenized Ti-50Al is very brittle and not good adherent. In Fig. 5, the $800^{\circ} \mathrm{C}$ isothermal oxidation curve of as-homogenized specimen, measured by the thermal gravimetric analysis (TGA) shows that the oxidation rate does not obey the parabolic law in the whole period of oxidation. This implies that, for the as-homogenized specimen, the oxidation reaction is not diffusion-controlled [16] and the protection of the oxide scale is poor, as reported previously [17]. Fig. 5 shows that the polishing treatment for the pre-oxidized Ti-50Al can dramatically reduce the oxidation rate at high temperature and its oxidation curve nearly fits well to the parabolic law. From Fig. 5, one can conclude that the outmost layer II of Fig. 3 is beneficial to the oxidation resistance.

The cross-sectional morphologies and element mappings of the specimen oxidized at $800^{\circ} \mathrm{C}$ for $100 \mathrm{~h}$ (indicated by the arrow in Fig. 5) are illustrated in Fig. 6. The thickness of the total oxide scale increases slightly from $2.9 \mu \mathrm{m}$ of Fig. 3(a) to $3.7 \mu \mathrm{m}$ of Fig. 6(a). Few titania crystals are observed on the outer surface of alumina-enriched layer. This implies that $\mathrm{Ti}$ atoms can diffuse through the alumina-enriched layer during the oxidation. Nevertheless, from the limited inward growth of oxide scale, the alumina-enriched layer can be considered to be a barrier for 


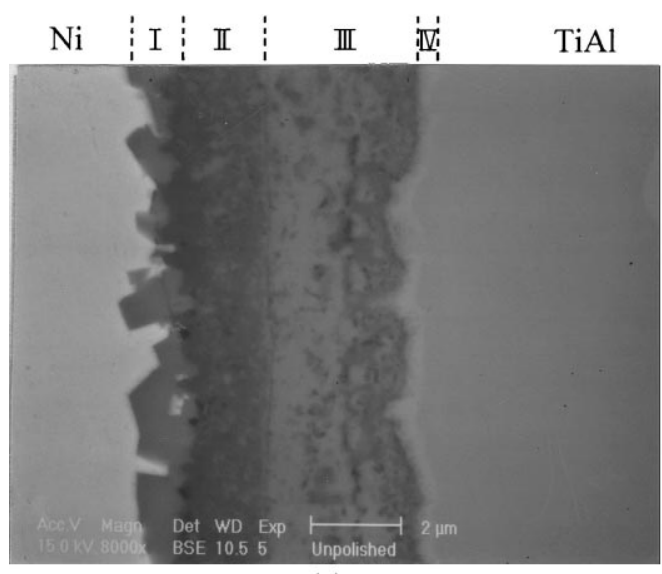

(a)

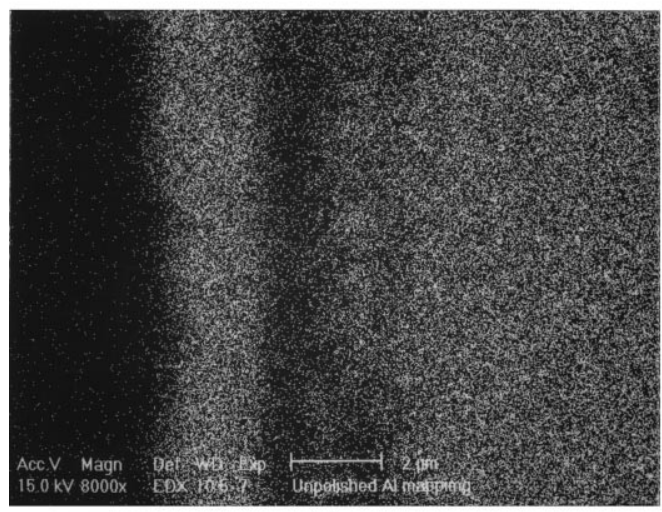

(c)

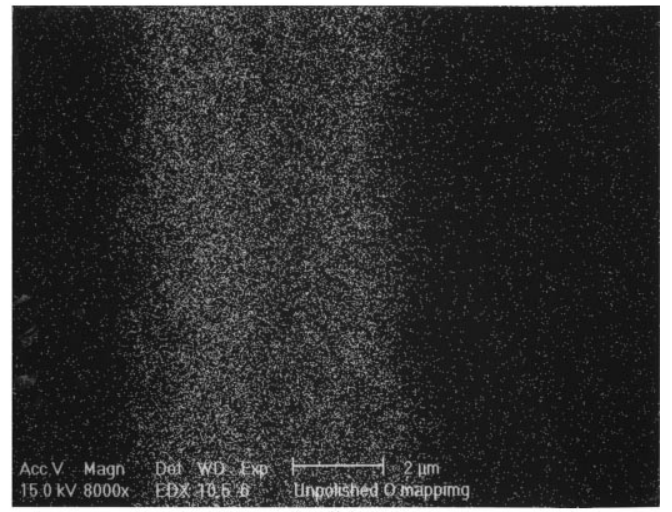

(b)

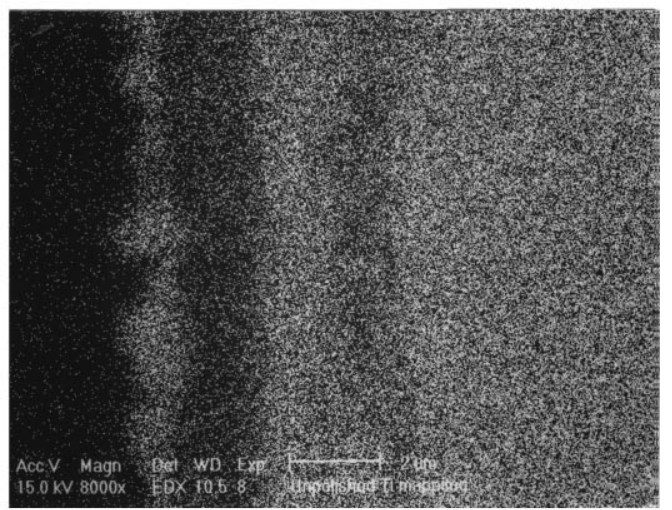

(d)

Fig. 2. Cross-sectional morphologies of Ti-50Al after oxidation at $800^{\circ} \mathrm{C}$ in air for $48 \mathrm{~h}$. (a) back-scattered electron image of the oxide scale and the base metal; (b) O mapping; (c) Al mapping; (d) Ti mapping.

oxygen diffusion to inhibit oxidation. In contrast to the result of as-homogenized specimen of Fig. 2, the outer rutile layer seems to be detrimental to the oxidation resistance of Ti-50Al intemetallics.

To evaluate the detrimental effect of the rutile layer (layer I of Fig. 2) on the oxidation resistance, pure thin Ti film was deposited on the specimen of Fig. 3 by rf sputtering process and then oxidized at $800^{\circ} \mathrm{C}$ for $100 \mathrm{~h}$ in air. Fig. 7 shows the cross section of the oxidized specimen with $\mathrm{Ti}$ coating. The stratified layers of the oxide scale in Fig. 7, similar to the Figs. 2 and 6, are characterized as an outer titania layer (I), an alumina-rich layer (II), an intermixed titania/alumina layer (III) and an Al-depleted layer (IV) at the interface of TiAl and oxide scale. In contrast to the Fig. 6, most of the titania in the outer layer (I) in Fig. 7 may result from the oxidation of the sputtered $\mathrm{Ti}(\cong 0.8 \mu \mathrm{m})$. From Fig. 7 , it can be found that the outer titania layer formed from the oxidation of sputtering-deposited Ti film, can accelerate the growth of oxide scale, as compared to the result of Fig. 6.

The Pilling-Bedworth ratios (PBR, volume ratios of oxide to metal) of $\mathrm{Al}_{2} \mathrm{O}_{3}$ and $\mathrm{TiO}_{2}$ are 1.28 and 1.73 , respectively
[18]. The value of PBR more than one can induce compressive stress in the oxide scale [18]. The compressive stress is a prerequisite for forming a condense and continuous oxide scale to protect the base metal against oxidation. However, the compressive stress on the scale will be balanced with the tensile stress around the interface between oxide scale and the base metal. When the tensile stress reaches a critical level, the stress will result in the rupture and/or spallation of oxide scale.

For the case of Fig. 7, the compressive stress induced by the oxidized $\mathrm{Ti}$ coating can further raise the stress level around the interface between the scale and metal and leads to the cracking or rupture of the scale, as shown by the arrow in Fig. 7(a). This causes the recurrence of serious spallation and elucidates the reason why the spallation of the oxide scale for as-homogenized Ti-50Al is more serious than that for the pre-oxidized and polished Ti-50Al, as explicitly shown in Fig. 5. Scale spallation or crack will facilitate fresh metal to expose oxidizing atmosphere and bring about faster degradation of base metals. On the contrary, for the case of Fig. 3, the outermost layer $\left(\mathrm{TiO}_{2}\right.$ layer) of Fig. 2 has been polished and 


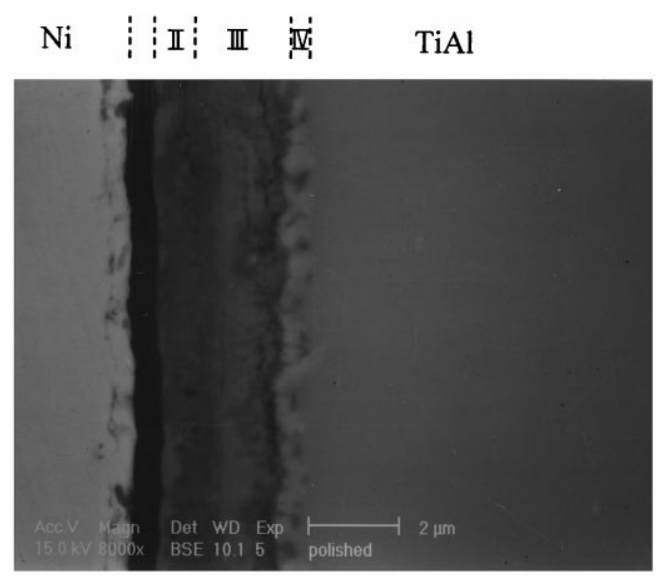

(a)

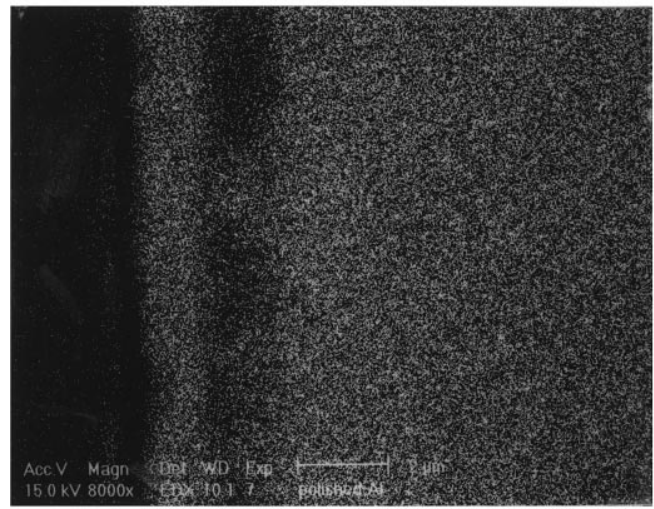

(c)

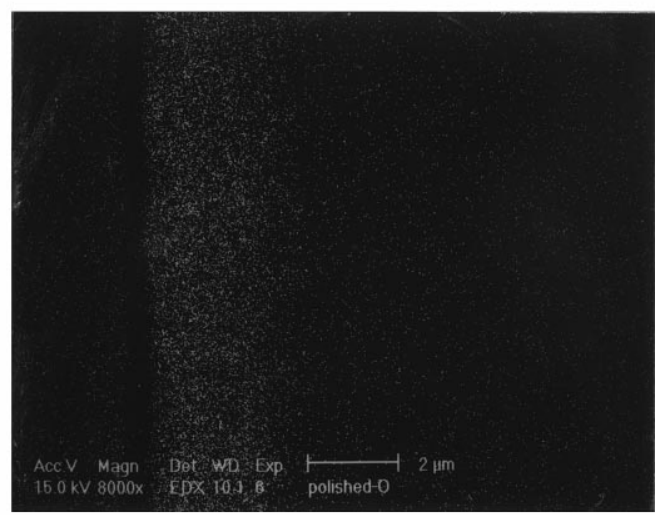

(b)

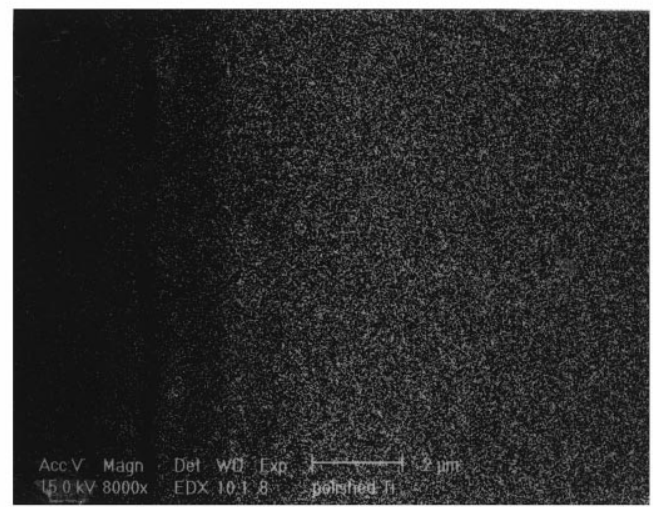

(d)

Fig. 3. Cross-sectional morphologies of Ti-50Al processed by polishing procedure after oxidation at $800^{\circ} \mathrm{C}$ in static air for $48 \mathrm{~h}$. (a) back-scattered electron image of the oxide scale and the base metal; (b) O mapping; (c) Al mapping; (d) Ti mapping.

the inherent compressive stress of $\mathrm{TiO}_{2}$ layer on the scale disappears. This feature causes the stress level of the inner oxide layers and that of the interface between the scale and metal to decrease simultaneously. This characteristic

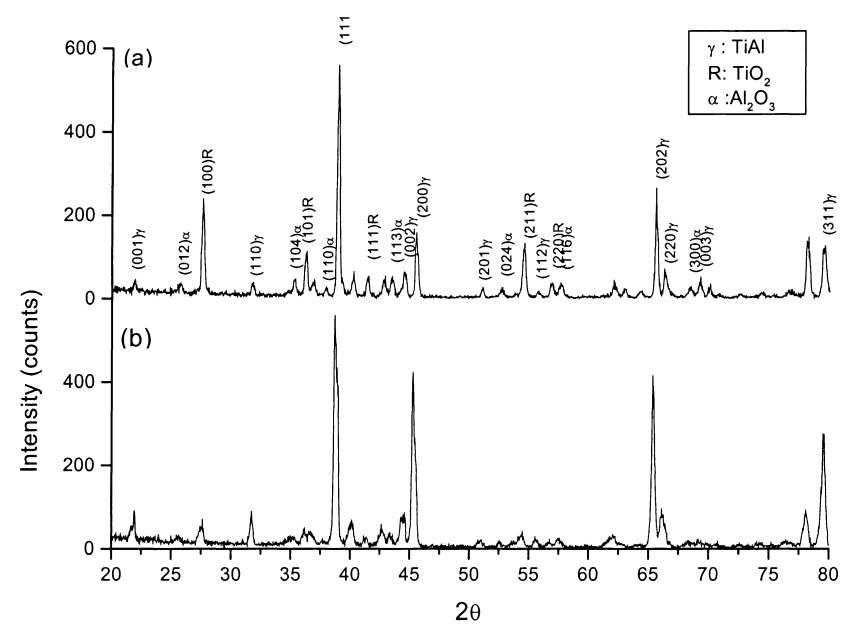

Fig. 4. X-ray diffraction patterns of Ti-50Al after oxidation at $800^{\circ} \mathrm{C}$ in air for $48 \mathrm{~h}$. (a) as-oxidized; (b) as-polished ( $\gamma$ : TiAl; $\mathrm{R}$ : $\mathrm{TiO}_{2} ; \alpha: \mathrm{Al}_{2} \mathrm{O}_{3}$ ). is a critical factor to mitigate oxidation of Ti-50Al intermetallics.

The compressive stress introduced by the additional outer $\mathrm{TiO}_{2}$ layer, as shown in Fig. 7, can enhance the diffusion rate through the oxide layers due to the stress-assisted diffusion [19]. This feature accelerates the oxidation kinetics of

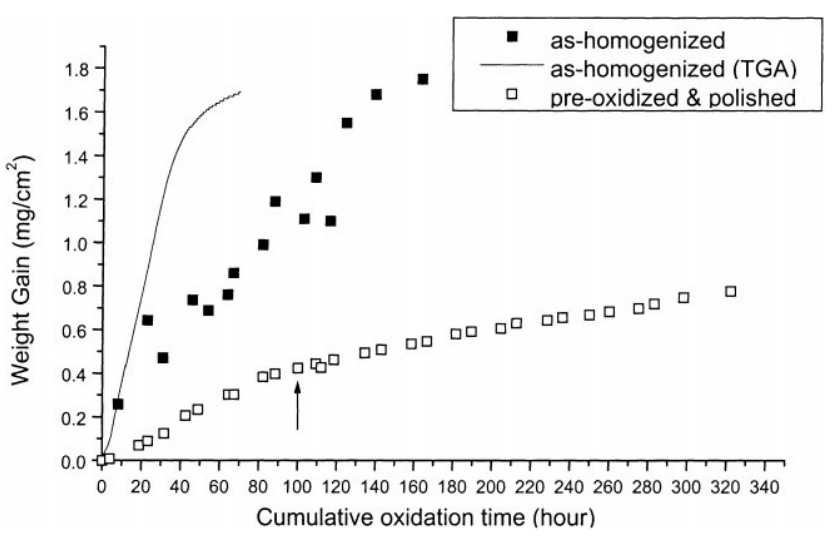

Fig. 5. Oxidation kinetics in static air at $800^{\circ} \mathrm{C}$ for $\mathrm{Ti}_{50} \mathrm{Al}_{50}$ alloy. 


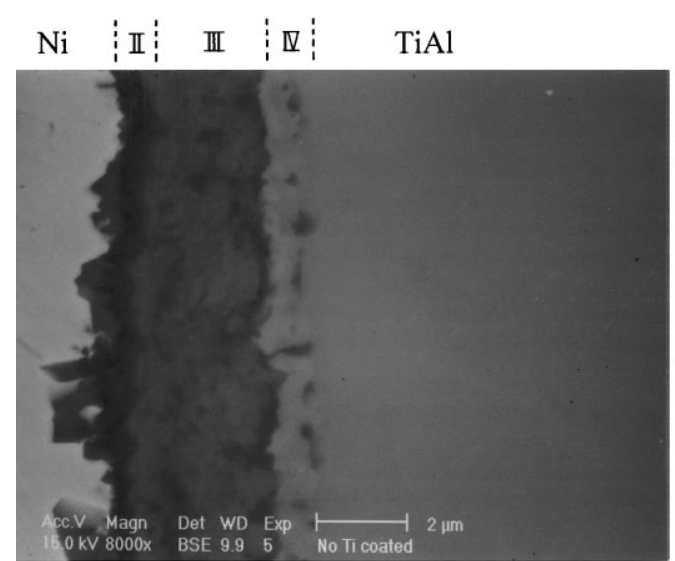

(a)

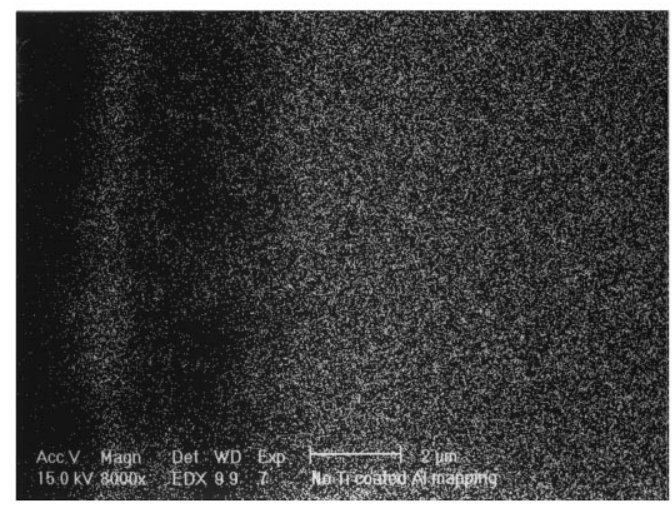

(c)

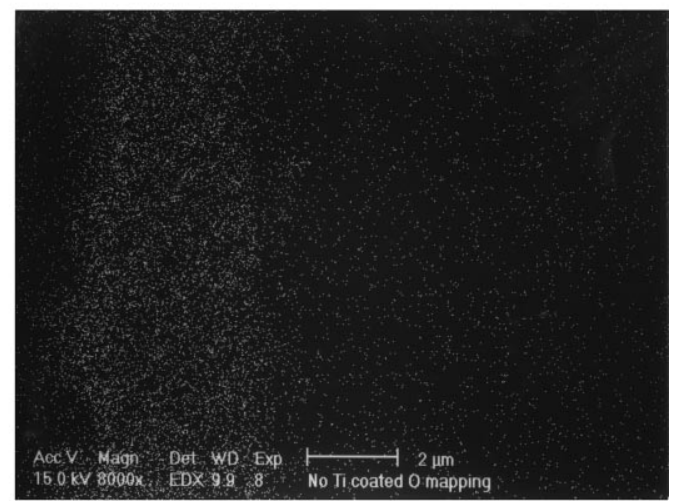

(b)

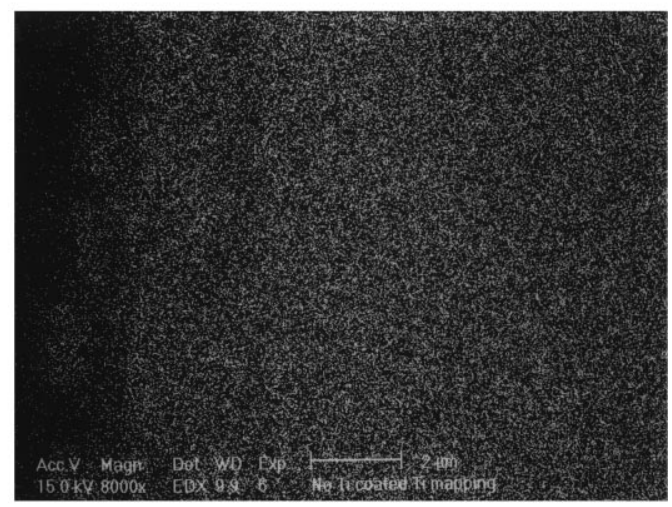

(d)

Fig. 6. Cross-sectional morphologies of polished Ti-50Al after oxidation at $800^{\circ} \mathrm{C}$ in air for $100 \mathrm{~h}$. (a) back-scattered electron image of the oxide scale and the base metal; (b) O mapping; (c) Al mapping; (d) Ti mapping.

TiAl by providing more reactants to oxidize, and therefore, disturbs the continuity of the $\mathrm{Al}_{2} \mathrm{O}_{3}$ scale and makes it less protective.

The detrimental effect of outer titania on the oxidation resistance of Ti-50Al intermetallics may also be associated with the well-known catalytic effect of rutile titania. The catalytic reaction of titania will favor the formation of ionic oxygen from the reaction, $\mathrm{O}_{2}+2 \mathrm{e}^{-} \rightarrow 2 \mathrm{O}^{-}$(weakly endothermic, $\cong 1 \mathrm{eV}$ ) [20], in contrast to the high bond energy of oxygen molecular, $5.15 \mathrm{eV}$ [21]. Moreover, the migrating species in oxide scale may be metal ions, oxygen ions and electrons [16]. Hence, ionic oxygen instead of atomic oxygen, will govern the diffusion through the oxide scale. That is, the rutile can facilitate the dissociation of oxygen molecules into ionic oxygen [20], thereby providing more ionic oxygen for diffusion. The increased flux of ionic oxygen will accelerate the inward growth of oxide layer, which is the main mechanism for the oxide growth on layer III $[22,23]$. The layer III observed in Fig. 7, which is comparatively wider than that in Fig. 6 provides the evidence to support this suggestion. Hence it can be concluded that, for the as-homogenized Ti-50Al, the poor protection of oxide scale may be attributed to the existence of an outer $\mathrm{TiO}_{2}$ scale, which may facilitate the catalytic effect of oxygen, increase the stress-assisted diffusion and introduce the compressive stress resulting in the fracture and/or cracking of oxide scale.

\section{Conclusions}

The oxidation resistance of Ti-50Al intermetallics can be improved by pre-oxidizing at $800^{\circ} \mathrm{C} \times 48 \mathrm{~h}$ in air and subsequently polishing the outer $\mathrm{TiO}_{2}$ layer of the oxide scale. Compared to the as-homogenized specimens, cyclic oxidation resistance at $800^{\circ} \mathrm{C}$ of the per-oxidized and polished specimens is substantially improved and the oxidation kinetics follow the parabolic rate law, indicating a diffusion-controlled process. This means that the outermost alumina-rich layer of the pre-oxidized and polished specimens is protective against oxidation at $800^{\circ} \mathrm{C}$ in air. This characteristic is attributed to the compressive stress relief associated with the removal of the outer $\mathrm{TiO}_{2}$ layer. The stress relief of the inner oxide layers will alleviate cracking or rupture of the scales and simultaneously reduce the stress-assisted diffusion in the scale. At the same time, the catalytic effect of the outer rutile titania, which favors the 


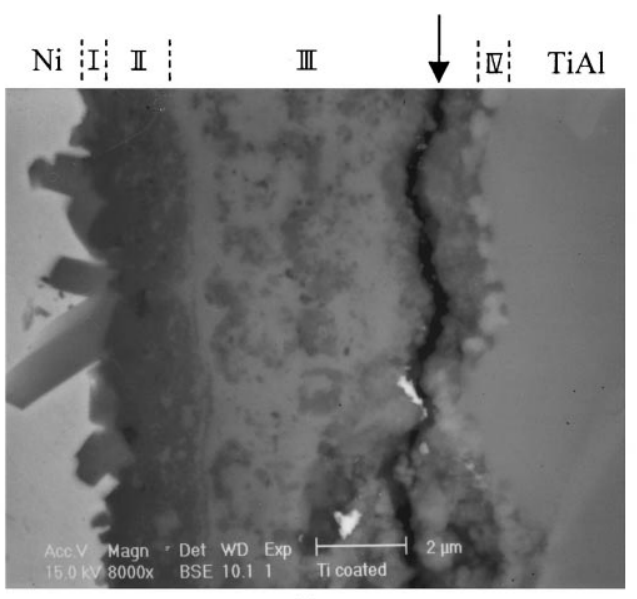

(a)

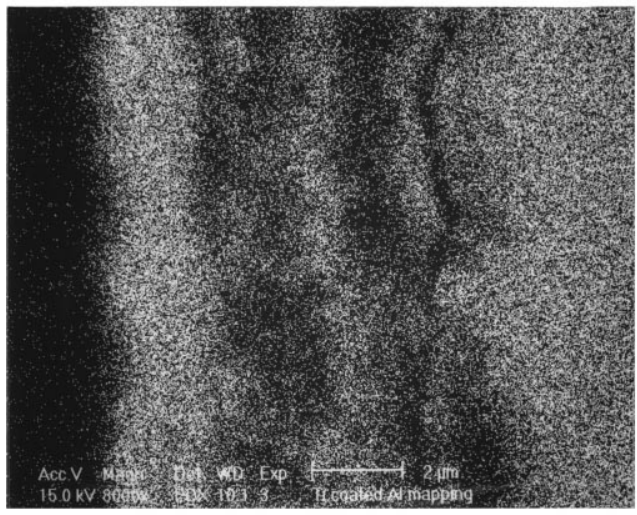

(c)

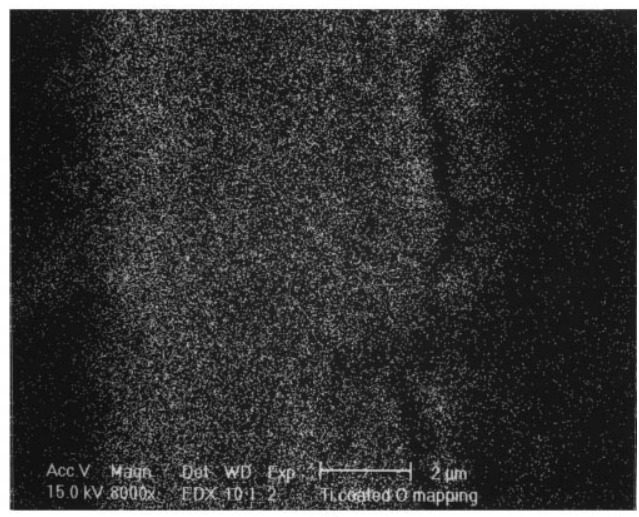

(b)

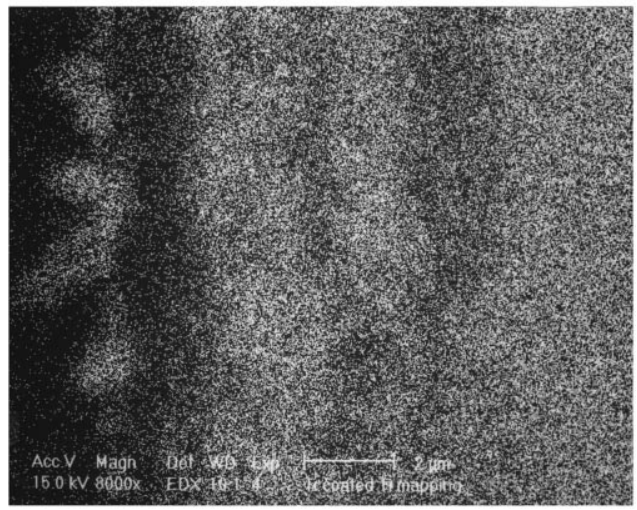

(d)

Fig. 7. Cross-sectional morphologies of polished Ti-50Al with $0.8 \mu \mathrm{m}$ Ti coating which has been oxidized at $800^{\circ} \mathrm{C}$ in air for $100 \mathrm{~h}$. (a) back-scattered electron image of the oxide scale and the base metal; (b) O mapping; (c) Al mapping; (d) Ti mapping.

dissociation of molecular oxygen into oxygen atoms, may also play a detrimental role on the oxidation resistance of TiAl at high temperature.

\section{Acknowledgements}

The authors are indebted to Dr. Shu-Chiao Tsai for the assistance of the experimental work. The authors are also pleased to acknowledge the financial support of this research by the National Science Council (NSC), Republic of China, under the Grant NSC88-2216-E002-026.

\section{References}

[1] Y.W. Kim, JOM 41 (7) (1989) 30.

[2] J.C. Beddoes, W. Wallace, M.C. de Malherebe, Mater. Manufacturing Process. 7 (4) (1992) 527.

[3] S.C. Huang, E.L. Hall, Metall. Trans. A 22A (1991) 427.

[4] S.C. Huang, E.L. Hall, Acta Metall. Mater. 39 (1991) 1053.

[5] Y.W. Kim, JOM 46 (7) (1994) 30.

[6] S. Taniguchi, T. Shibata, K. Nakamura, X.-H. Liu, Z.-H. Zheng, W. Huang, S.-C. Zou, Mater. Sci. Eng. A120 (1989) 519.

[7] E. Kobayashi, M. Yoshihara, R. Tanaka, High Temp. Tech. 8 (3) (1990) 179.
[8] H. Anada, Y. Shida, Mater. Trans. JIM 36 (4) (1995) 553.

[9] Y. Shida, H. Anada, Mater. Trans. JIM 34 (3) (1993) 236.

[10] J.M. Rakowski, F.S. Pettit, G.M. Meire, F. Dettenwanger, E. Schumann, M. Ruhle, Script Met. et Mater. 33 (1995) 997.

[11] S. Taniguchi, T. Shibata, K. Takeuchi, Mater. Trans. JIM 32 (3) (1991) 299.

[12] S. Taniguchi, T. Shibata, S. Sakon, Mater. Sci. Eng. A198 (1995) 85.

[13] S. Taniguchi, T. Shibata, A. Murakami, K. Chihara, Oxid. Metals 42 (1-2) (1994) 17.

[14] S. Taniguchi, T. Shibata, A. Murakami, Oxid. Metals 41 (1/2) (1994) 103.

[15] G.E. Co., US Patent 4,780,342, 25 October 1988.

[16] P. Kofstad, High Temperature Corrosion, Elsevier, Amsterdam, 1988, p. 164.

[17] T. Shimizu, T. Iikubo, S. Isobe, Mater. Sci. Eng. A153 (1992) 602.

[18] P. Kofstad, High Temperature Corrosion, Elsevier, Amsterdam, 1988, p. 244.

[19] P.G. Shewmon, Diffusion in Solids, McGraw-Hill, New York, 1963, p. 23.

[20] V.F. Kiselev, O.V. Krylov, Adsorption and Catalysis on Transition Metals and Their Oxides, Springer, New York, 1989, p. 177.

[21] P.W. Atkins, Physical Chemistry, Oxford University Press, New York, 1994, p. 80.

[22] S. Taniguchi, T. Shibata, S. Itoh, Mater. Trans. JIM 32 (2) (1991) 151.

[23] C. Jin, W.J. Chen, K.L. Jing, X.J. Wan, Script Met. et Mater. 29 (1993) 747 